\title{
Behavioural climate policy
}

\author{
SANDER VAN DER LINDEN * \\ Department of Psychology, University of Cambridge, Cambridge, UK \\ ADAM R. PEARSON (iD \\ Department of Psychological Sciences, Pomona College, Claremont, CA, USA \\ LEAF VAN BOVEN (D) \\ Department of Psychology and Neuroscience, University of Colorado, Boulder, CO, USA
}

Global climate change is the largest existential threat of our time. Glaciers are retreating, sea levels are rising, extreme weather is intensifying and the last four years have been the hottest on record (NASA, 2020; World Meteorological Organization, 2020). Although climate change is already significantly impacting natural and human systems around the world, mitigating further and potentially disastrous climate change will require large-scale individual and collective action, including public support for mitigation policies, as well as the more rapid development and implementation of adaptation plans (van der Linden et al., 2015; Pearson et al., 2016).

Against this backdrop, the USA, one of the world's largest producers of fossil fuels, is set to withdraw from the 2015 United Nations Framework Convention on Climate Change (UNFCCC) Paris Agreement on 4 November 2020, before the next United Nations Conference of Parties (COP 26) will convene in Glasgow, Scotland. The Intergovernmental Panel on Climate Change (IPCC) is currently in its sixth assessment cycle (with a synthesis report for policymakers scheduled for 2022, in time for the first global stocktake under the Paris Agreement). However, a 2018 special report already warned that global warming is likely to breach the $1.5^{\circ} \mathrm{C}$ threshold between 2030 and 2052 if warming continues at current rates (IPCC, 2018). Accordingly, global emissions must be reduced to net-zero by 2050 to meet key emissions targets; yet, only eight nations to date have instituted a national policy framework or passed legislation to help reach this target (World Economic Forum, 2019).

In this special issue, we showcase what behavioural science has to offer to help achieve large-scale behaviour change and policy support. As others

\footnotetext{
* Correspondence to: Department of Psychology, School of Biological Sciences, University of Cambridge, Cambridge CB2 3EB, UK. E-mail: sander.vanderlinden@psychol.cam.ac.uk
} 
have noted (e.g., Levin et al., 2012), climate change presents a unique challenge for policymaking for several reasons, including the relatively short window to act (and long-lag consequences for both action and inaction); the fact that those seeking to address the problem are also contributing to it; and, given the complexity and scale of climate change, the need for a truly global response. As such, traditional policy tools, such as relying on local market mechanisms to raise the price of carbon and drive technological change, may be insufficient, or they may operate on too slow of a timeframe to meet key adaptation and mitigation targets.

A few observations are crucial in motivating this special issue. The first is that although behavioural science can make significant contributions to reducing greenhouse gas emissions, creating a 'behavioural wedge' for larger policy changes (Dietz et al., 2009), it is noteworthy that behavioural scientists (especially psychologists) have played little role in the IPCC reports until recently. Elke Weber (a contributor to this special issue) was the first psychologist to be included as a lead author in the fifth assessment report. As Baruch Fischhoff (this issue) notes, "we need to treat climate science as a behavioural endeavor." The second is that climate change remains a highly politicized issue in major emitting countries such as the USA (Ballew et al., 2019). Accordingly, research has focused on trying to understand more basic processes, such as group polarization and science denial, which pose substantial barriers to developing and enacting bipartisan climate policy (Ehret et al., 2018). A consequence of this trend has been that policymakers have traditionally shied away from nudging climate policy (van der Linden, 2018), noting that climate change is going to need 'more than a nudge'. Behavioural research that has focused on changing actual behaviour has shown some promise, for example, through climate-friendly defaults (Sunstein \& Reisch, 2014; Kaiser et al., 2020), but a recent meta-analysis of randomized controlled trials testing a wide variety of behavioural interventions between 1976 and 2017 concluded that average effect sizes are small, with low uptake and little evidence of sustained positive effects post-intervention (Nisa et al., 2019). However, most studies included in the meta-analysis examine arguably lowimpact behaviours, and the study of behavioural interventions in this area is relatively young compared to other fields, so existing studies may fail to capture the potential of behavioural interventions on a larger scale (Stern, 2020; van der Linden \& Goldberg, 2020).

Accordingly, it is fair to say that there is more work to be done beyond 'trivial interventions' (Oliver, 2017), and that the opportunities for advancing behavioural climate policy are many and varied. This special issue seeks to advance novel insights on this front. We need behavioural scientists of all stripes to advance our knowledge of how to overcome polarization (e.g., 
Sunstein et al., 2016), as people's beliefs about science and each other are intricately linked to policy support (Van Boven et al., 2018; van der Linden et al., 2019), but we also need research that advances our understanding of how to engage and influence policymakers, as well as how to change consumer behaviour and mobilize public support directly. The contributions in this special issue reflect each of these efforts. Together, they advance a framework for behavioural climate policy centred around three pillars: (1) removing social and partisan barriers to policy design and implementation; (2) developing, evaluating and disseminating interventions that target consumer behaviour; and (3) complementing behavioural nudges by facilitating local and deliberative decisionmaking. We hope that the field will benefit from organizing and strengthening the efforts of behavioural scientists in each of these areas.

\section{Removing social and partisan barriers to policy design and implementation}

The first pillar for behavioural scientists is to identify, understand and remove partisan and other social barriers to policy design and implementation. A 'topdown' perspective highlights how politicians and other political elites communicate to the broader public about the importance of enacting climate policy and its design. Rinscheid et al. (this issue) argue, for example, that political parties in the USA can bolster public support for specific climate policies such as phasing out fossil fuel vehicles and the deployment of carbon capture and storage, but only to the extent that people trust the parties involved. Their findings highlight the importance of trust in politicians and other experts as a moderating factor in support for climate policy.

A 'bottom-up' perspective highlights how local activists and grassroots efforts can motivate both the broader public and political elites to support climate policies. Sherman and colleagues (this issue) discuss four behaviourally 'wise' (Walton \& Wilson, 2018) strategies - affirmation, social norms, legacy and immediacy - that citizen activists can use to convince policymakers to support climate policy. They summarize an exploratory study with a grassroots citizen lobbying organization, providing evidence for the resonance of these strategies and highlighting social psychological factors that influence whether and with what success grassroots activists implement these strategies in their lobbying efforts.

In addition to understanding social barriers within traditional political hierarchical structures, other papers demonstrate the importance of 'side-to-side' influence on support for climate policy. Rabb et al. (this issue) show that public understanding of climate change and climate policy rests largely on perceptions that individuals within one's broader community understand climate change. This 'community of knowledge' hypothesis can undergird support for 
climate policy. Similarly, Goldberg and colleagues (this issue) explore public attitudes towards climate policy, finding that perceptions of injunctive social norms about climate policy - the stances and behaviours that are approved or disapproved of by one's political in-group - are among the strongest predictors of support for climate policy in the USA, especially among Republicans. This finding may be especially important in light of recent evidence that conservative attitudes towards climate change may be less stable and more changeable than liberals' attitudes (Jenkins-Smith et al., 2020). Of course, social norms and community effects might not only influence policy support, but might also directly influence consumer behaviour.

\section{Policy interventions for consumer behaviour}

The second pillar that behavioural scientists can address is the design of policy interventions to change consumer behaviour. There is significant potential for large-scale reductions in emissions if such behavioural changes are implemented at national and international scale. For example, studies estimate that behavioural interventions can reduce up to $20 \%$ of residential emissions in the USA alone (Dietz et al., 2009). Globally, human consumption and waste patterns, including food, energy and transportation use, and their indirect effects on supply chains, are estimated to account for up $60 \%$ of global greenhouse gas emissions (Ivanova et al., 2016).

One key insight from this special issue is the importance of the social context in which people make consumer decisions. For example, Sparkman et al. (this issue) point out that, as a social dilemma, climate change is fundamentally a problem of vicious and virtuous behaviour cycles. Critically, Sparkman and colleagues highlight that many unsustainable behaviours, such as driving and meat consumption, remain the current norm. So how can we change societal norms around unsustainable behaviours? Sparkman et al. suggest that people's tendency to conform to trends (i.e., dynamic norms) and signals that others are working towards a common goal can both increase sustainable behaviour, even if that behaviour is currently counter-normative. Yet, at the same time, norm interventions must be carefully designed. As Rinscheid et al. note in this special issue, normative messages do not always produce the intended effect, and norms that communicate the prevalence of nonsustainable behaviours can decrease consumer support for de-carbonization policies, such as proposals to phase out fossil fuel-based cars. Together, these papers highlight that consumer behaviours are embedded in social contexts that must be carefully understood and navigated.

As Fischhoff (this issue) recommends, behavioural insights need to be translated into quantitative estimates that climate models can work with. This 
involves estimating and focusing on the emissions-reduction potential of different behaviours (high- versus low-impact behaviours) and the likelihood that people who are in a position to do so will actually adopt the suggested behaviour (i.e., 'behavioural plasticity'). It has become increasingly clear that behavioural interventions are more likely to be effective when both cognitive and contextual barriers to decision-making are reduced (Stern, 2020), which requires a more careful consideration of the social, economic and institutional contexts in which people make decisions and the need to consider behavioural insights at all stages of the policy process.

\section{Local and deliberative decision-making}

Behavioural approaches to climate policy have largely focused on what policies would be effective, for example, by increasing policy compliance at lower cost through the provision of tailored information, appeals to norms, and goalsetting (see Howlett \& Rawalt, 2019). Considerably less attention has been paid to the process of policy design (see Fischhoff, this issue), which is an unfortunate oversight. Behavioural scientists have much expertise in how to structure group processes (e.g., Sunstein \& Hastie, 2015) and negotiation (Bazerman et al., 2000) to achieve desirable, stable outcomes. Applying such behavioural insights to the process of policy design - from agenda-setting and policy formulation to implementation and evaluation - is an important opportunity for behavioural scientists.

Árvai and Gregory (this issue) highlight structured decision-making as a means to identify and balance key trade-offs in climate change decisionmaking between different stakeholders who must balance often conflicting economic, social and environmental objectives. There has been scant research on how to make better climate risk management decisions, in contrast with the larger literature on managing risk in business contexts. Moreover, policy decisions are often based on misperceptions about what a target population needs or prefers (Schneider \& Ingram, 1993). Rather than focusing on ways to remove obstacles to high-quality decisions or to simply educate people to better understand risks (Reijula et al., 2018), they describe a framework to help decision-makers work with stakeholders to organize and prioritize policy aims to produce better, more defensible policy solutions. They illustrate this approach with two case examples - energy system transitions and adaptation to sea-level rise - that used structured processes to encourage deliberative decision-making. These procedures may also help to address a common concern behind choice architecture and other behavioural interventions: that stakeholder engagement is merely a façade behind which real decisions are being made (Renn et al., 1993). 


\section{Scaling behavioural approaches to climate policy}

The articles in this issue make some progress towards answering critical questions while exposing key knowledge gaps. How can we make climate science, including behavioural science, more relevant to policymakers? How can we balance the specificity of what policymakers need with what behavioural scientists can realistically offer?

Although behavioural interventions are promising, important questions remain about their durability and cumulative impact. For instance, it remains to be seen whether technological change - and behavioural interventions to speed such changes - leads to a growth or reduction in emissions through consumer behaviour. Renewables are currently the cheapest source of new power generation in much of the world, with utility-scale solar and wind set to outcompete existing coal plants in cost savings in 2020 (UNEP, 2019). Yet, cost savings associated with technology improvements, such as the use of more fuel-efficient cars, can sometimes lead to increased emissions and lower mitigation effort (i.e., rebound effects; Fisher-Vanden \& Ho, 2010). Similarly, recent advances in new carbon removal technologies, socalled negative emissions technologies (NETs; National Academies of Sciences, Engineering, and Medicine, 2019), may be viewed as a future failsafe for deficient mitigation and adaptation planning. How policymakers - and their target audiences - understand and prioritize both the near- and longterm impacts of different climate policies remain critical questions for behavioural science.

Moreover, there is a need for testing the effectiveness of behavioural interventions at both individual and macro levels and considering the contexts in which behaviours may become more 'plastic'. A growing literature suggests that the most effective ways to use behavioural interventions to change household actions that affect emissions are not alone, but in combination with economic, regulatory and other non-behavioural interventions (Wolske \& Stern, 2018). For example, life transitions, such as relocating or starting a new job, offer a unique window of opportunity to disrupt or alter habits and consumption patterns (Bamberg, 2006). Whether other large-scale social disruptions present similar opportunities for behavioural intervention, including changes in consumer behaviour and speeding the development and adoption of new climate policies, remains an important open question.

As Fischhoff (this issue) reminds us, all sciences have two subjective elements: professional judgements, which inform how we interpret data; and value judgements, which determine which issues are studied and prioritized and how cautiously results are interpreted. Behavioural science can help scientists and decision-makers navigate both elements to craft more effective and 
equitable policies. Yet Fischhoff also reminds us that in order to represent public and scientific concerns, behavioural scientists need to participate in policy discussions, becoming "players in shaping policies, and not just conveyors." The good news is that behavioural policy interventions are increasingly appreciated by policymakers (Oliver, 2017), with over a dozen national governments having integrated behavioural science in the crafting and dissemination of environmental policy (Organisation for Economic Cooperation and Development, 2017). The articles in this special issue highlight both new insights as well as untapped opportunities for leveraging behavioural science to meet one of the defining social challenges of our time. The timing is ripe for behavioural climate policy.

\section{References}

Árvai, J. and R. Gregory (this issue), 'Beyond choice architecture: A building code for structuring climate risk management decisions', Behavioural Public Policy.

Ballew, M.T., A. Leiserowitz, C. Roser-Renouf, S. A. Rosenthal, J. E. Kotcher, J. R. Marlon, E. Lyon, M. H. Goldberg and E. W. Maibach (2019), 'Climate change in the American mind: Data, tools, and trends', Environment: Science and Policy for Sustainable Development, 61(3): 4-18.

Bamberg, S. (2006), 'Is a residential relocation a good opportunity to change people's travel behavior? Results from a theory-driven intervention study', Environment and Behavior, 38(6): 820-840.

Bazerman, M. H., J. R. Curhan, D. A. Moore and K. L. Valley (2000), 'Negotiation', Annual Review of Psychology, 51(1): 279-314.

Dietz, T., G. T. Gardner, J. Gilligan, P. C. Stern and M. P. Vandenbergh (2009), 'Household actions can provide a behavioral wedge to rapidly reduce US carbon emissions', Proceedings of the National Academy of Sciences, 106(44): 18452-18456.

Ehret, P.J., L. Van Boven and D. K. Sherman (2018), 'Partisan barriers to bipartisanship: Understanding climate policy polarization', Social Psychological and Personality Science, 9(3): 308-318.

Fischhoff, B. (this issue) 'Making Behavioral Science Integral to Climate Science and Action', Behavioural Public Policy.

Fisher-Vanden, K and M. S. Ho (2010), 'Technology, development, and the environment', Journal of Environmental Economics and Management, 59(1): 94-108.

Goldberg, M., A. Gustafson, M.T. Ballew, S.A. Rosenthal and A. Leiserowitz (this issue), 'Identifying the most important predictors of support for climate policy in the United States', Behavioural Public Policy.

Howlett, M and S. Rawat. (2019), 'Behavioral Science and Climate Policy.' In Oxford Research Encyclopedia of Climate Science. 10.1093/acrefore/9780190228620.013.624

IPCC (2018), "Global Warming of $1.5^{\circ}$ C: An IPCC Special Report on the Impacts of Global Warming of $1.5^{\circ} \mathrm{C}$ Above Pre-industrial Levels and Related Global Greenhouse Gas Emission Pathways, in the Context of Strengthening the Global Response to the Threat of Climate Change, Sustainable Development, and Efforts to Eradicate Poverty". IPCC. Retrieved from https://www.ipcc.ch/sr15/

Ivanova, D., K. Stadler, K. Steen-Olsen, R. Wood, G. Vita, A. Tukker and E. G. Hertwich (2016), 'Environmental impact assessment of household consumption', Journal of Industrial Ecology, 20(3): 526-536. 
Jenkins-Smith, H. C., J. T. Ripberger, C. L. Silva, D. E. Carlson, K. Gupta, N. Carlson, A. Ter-Mkrtchyan and R. E. Dunlap (2020), 'Partisan asymmetry in temporal stability of climate change beliefs', Nature Climate Change, 1-7.

Kaiser, M., M. Bernauer, C. R. Sunstein and L. A. Reisch (2020), 'The power of green defaults: the impact of regional variation of opt-out tariffs on green energy demand in Germany'. Ecological Economics, 174: 106685.

Levin, K., B. Cashore, S. Bernstein and G. Auld (2012), 'Overcoming the tragedy of super wicked problems: constraining our future selves to ameliorate global climate change', Policy Sciences, 45(2): 123-152.

NASA (2020) "The effects of climate change". Retrieved from https:/climate.nasa.gov/effects/

National Academies of Sciences, Engineering, and Medicine (2019), Negative Emissions Technologies and Reliable Sequestration: A Research Agenda, Washington, DC: The National Academies Press. https://doi.org/10.17226/25259.

Nisa, C. F., J. J. Bélanger, B. M. Schumpe and D. G. Faller (2019), 'Meta-analysis of randomised controlled trials testing behavioural interventions to promote household action on climate change', Nature Communications, 10(1): 1-13.

Oliver, A. (2017), The Origins of Behavioural Public Policy, Cambridge University Press, Cambridge, UK.

Organisation for Economic Co-operation and Development (2017). Tackling environmental problems with the help of behavioural insights, OECD Publishing. https://doi.org/10.1787/ 9789264273887-en

Pearson, A. R., J. P. Schuldt and R. Romero-Canyas (2016), 'Social climate science: A new vista for psychological science', Perspectives on Psychological Science, 11(5): 632-650.

Rabb, N., J.J. Han and S. Sloman (this issue), 'How others drive our sense of understanding of policies', Behavioural Public Policy.

Reijula, S., J. Kuorikoski, T. Ehrig, K. Katsikopoulos and S. Sunder (2018), 'Nudge, Boost, or Design? Limitations of behaviorally informed policy under social interaction', The Journal of Behavioral Economics for Policy, 2(1).

Renn O, Webler T, Rakel H, Dienel P and Johnson B (1993),'Public participation in decision making: a three step procedure', Policy Sciences, 26: 189-214.

Rinscheid, A., S. Pianta and E.U. Weber (this issue), 'What shapes public support for climate change mitigation policies? The role of descriptive social norms and elite cues', Behavioural Public Policy.

Schneider, A. and H. Ingram (1993), 'Social construction of target populations: Implications for politics and policy.' American Political Science Review, 87(2): 334-347.

Sherman, D., M. F. Shteyn, H. Han and L. Van Boven (this issue), 'The exchange between citizens and elected officials: a social psychological framework for citizen climate activists', Behavioural Public Policy.

Sparkman, G., L. Howe and G. Walton (this issue), 'How social norms are often a barrier to addressing climate change but can be part of the solution', Behavioural Public Policy.

Stern, P. C. (2020), 'A reexamination on how behavioral interventions can promote household action to limit climate change' Nature Communications, 11(1): 1-3.

Sunstein, C. R. and R. Hastie (2015), Wiser: Getting beyond groupthink to make groups smarter, Harvard Business Press.

Sunstein, C. R. and L. A. Reisch (2014), 'Automatically green: Behavioral economics and environmental protection', Harv. Envtl. L. Rev. 38: 127-157.

Sunstein, C. R., S. Bobadilla-Suarez, S. C. Lazzaro and T. Sharot (2016), 'How people update beliefs about climate change: Good news and bad news', Cornell L. Rev. 102: 1431-1441.

United Nations Environment Program (UNEP, 2019), “Emissions Gap Report 2019”, UNEP Nairobi. Retrieved from https://wedocs.unep.org/bitstream/handle/20.500.11822/30797/EGR2019.pdf 
Van Boven, L., P. J. Ehret and D. K. Sherman (2018),'Psychological barriers to bipartisan public support for climate policy', Perspectives on Psychological Science, 13(4): 492-507.

van der Linden, S. (2018), 'The future of behavioral insights: on the importance of socially situated nudges', Behavioural Public Policy, 2(2): 207-217.

van der Linden, S. and M. Goldberg (2020), Alternative meta-analysis of behavioural interventions to promote action on climate change yields different conclusions. Nature Communications, 11: 3915.

van der Linden, S., E. Maibach and A. Leiserowitz (2015), 'Improving public engagement with climate change: Five "best practice" insights from psychological science', Perspectives on Psychological Science, 10(6): 758-763.

van der Linden, S., A. Leiserowitz and E. Maibach (2019), 'The gateway belief model: A large-scale replication', Journal of Environmental Psychology, 62: 49-58.

Walton, G. M. and T.D. Wilson (2018), 'Wise interventions: Psychological remedies for social and personal problems', Psychological Review, 125(5): 617-655.

Wolske, K.S. and P.C. Stern (2018) "Contributions of psychology to limiting climate change: Opportunities through consumer behavior", in S. Clayton and C. Manning (eds), Psychology and Climate Change: Human Perceptions, Impacts, and Responses. Elsevier Academic Press, 127-160.

World Economic Forum (WEF, 2019), "Who's promised net zero, and who looks likely to get there?" Retrieved from https://www.weforum.org/agenda/2019/12/countries-companies-net-zerocarbon-emissions/

World Meteorological Organization (2020), "WMO Statement on the State of the Global Climate in 2019”. WMO-No. 1248. Retrieved from https:/library.wmo.int/doc_num.php?explnum_ id $=10211$ 